03

\title{
Экспериментальное исследование дозвуковых микроструй, истекающих из плоского сопла
}

\author{
() В.М. Анискин ${ }^{1,2}$, А.А. Маслов ${ }^{1,2}$, К.А. Мухин ${ }^{1}$ \\ ${ }^{1}$ Институт теоретической и прикладной механики им. С.А. Христиановича \\ СО РАН, Новосибирск \\ ${ }^{2}$ Новосибирский государственный университет \\ E-mail: aniskin@itam.nsc.ru
}

Поступило в Редакцию 12 апреля 2017 г.

Выполнены эксперименты по исследованию дозвуковых ламинарных микроструй, истекающих из плоского сопла. Размер сопла составлял $83.3 \times 3600 \mu \mathrm{m}$. Числа Рейнольдса, вычисленные по высоте сопла и средней скорости потока на срезе сопла, составляли от 58 до 154. Рабочим газом являлся воздух комнатной температуры. Определено распределение скорости и пульсаций скорости газа вдоль осевой линии струи. Показано принципиальное отличие полученных характеристик ламинарных дозвуковых микроструй от турбулентных струй макроразмера. На основе измерений пульсаций скорости показано наличие ламинарно-турбулентного перехода и определено его местоположение.

DOI: 10.21883/PJTF.2017.14.44817.16502

Современная тенденция к миниатюризации технических устройств различного приложения пробуждает интерес к изучению течения жидкости и газа на микромасштабах. Поскольку реализуемые скорости жидкости и газа в этой области, как правило, невелики, то такое движение характеризуется малыми значениями чисел Рейнольдса. Дозвуковые и сверхзвуковые микроструйные течения, вследствие их 
возможности применения для управления макротечениями, в струйных системах охлаждения, позиционирования микроспутников, находятся в зоне внимания [1-7].

Экспериментальных работ по исследованию турбулентных струй макроразмера, истекающих из сопел прямоугольной формы, достаточно много (см. [8] и ее ссылки). В литературе рассматривались вопросы влияния соотношения сторон сопла, числа Рейнольдса, формы сопла, наличия и отсутствия боковых стенок и другие на характер распространения турбулентной струи. По характеру поведения скорости на осевой линии турбулентной макроструи выделяют три основные области: первая - область потенциального течения, где скорость струи не изменяется вдоль осевой линии; вторая - характерная область струи, где темп падения скорости пропорционален $(x / h)^{-0.5}(x-$ расстояние от среза сопла, $h$ - высота сопла) и третья - область, где струя становится квазиосесимметричной и темп падения скорости пропорционален $(x / h)^{-1}$. Экспериментальных работ по исследованию дозвуквых ламинарных микроструй, истекающих из сопел прямоугольной формы, единицы $[4,5]$. В данных работах использовалось сопло высотой 50 и длиной $2000 \mu \mathrm{m}$. Часть результатов данных работ, в частности распределение скорости вдоль осевой линии струи, вызывает сомнение в достоверности. Существует ряд работ, объединенных в монографию [6] и посвященных устойчивости министруй при различном воздействии на них. Однако в них отсутствуют данные по основным характеристикам свободных струй.

Целью данной работы является расширение представления о поведении плоских струй на микромасштабе и определение их основных характеристик: распределение скорости и пульсаций скорости газа вдоль осевой линии струи при различных числах Рейнольдса.

На основе технологии, разработанной в [1], изготовлено двумерное микросопло. Сопло имело цилиндрическую форкамеру диаметром $4 \mathrm{~mm}$ и клиновидно сужающуюся сопловую часть. Высота сопла $h$ составляла $83.3 \mu \mathrm{m}$, ширина сопла $w-3823 \mu \mathrm{m}$. Соотношение сторон $h / w=46$.

Исследование дозвуковой микроструи осуществлялось с помощью термоанемометра. Датчик термоанемометра имел длину вольфрамовой нити $200 \mu \mathrm{m}$ и диаметр $2 \mu \mathrm{m}$. Тарировка датчика проводилась на специально изготовленной для этой цели миниатюрной аэродинамической трубе, располагавшейся рядом с микросоплом. Диаметр выходного

Письма в ЖТФ, 2017, том 43, вып. 14 

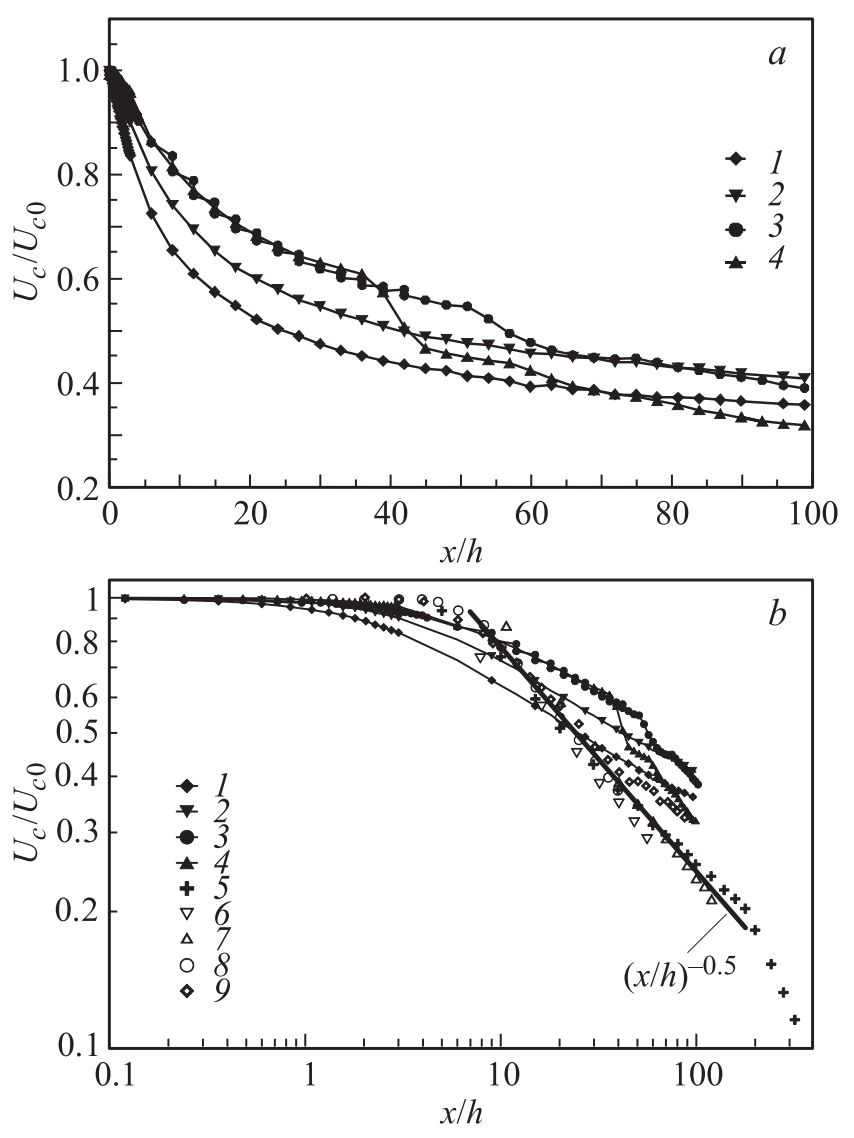

Рис. 1. Распределение скорости газа вдоль осевой линии струи в линейном $(a)$ и логарифмическом $(b)$ масштабах. Числа Рейнольдса: $1-58 ; 2-88 ; 3-$ $130 ; 4-154 ; 5-17800, h / w=40[9] ; 6-2770, h / w=40[10] ; 7-30000$, $h / w=38.5[11] ; 8-81400, h / w=44[12] ; 9-1800, h / w=40[13]$.

сечения трубы $5.5 \mathrm{~mm}$. Тарировка датчика проводилась до и после эксперимента. Датчик термоанемометра крепился к державке (нить датчика располагалась параллельно большой оси сопла) и перемещался в пространстве вдоль осевой линии с помощью микроманипулятора

Письма в ЖТФ, 2017, том 43, вып. 14 


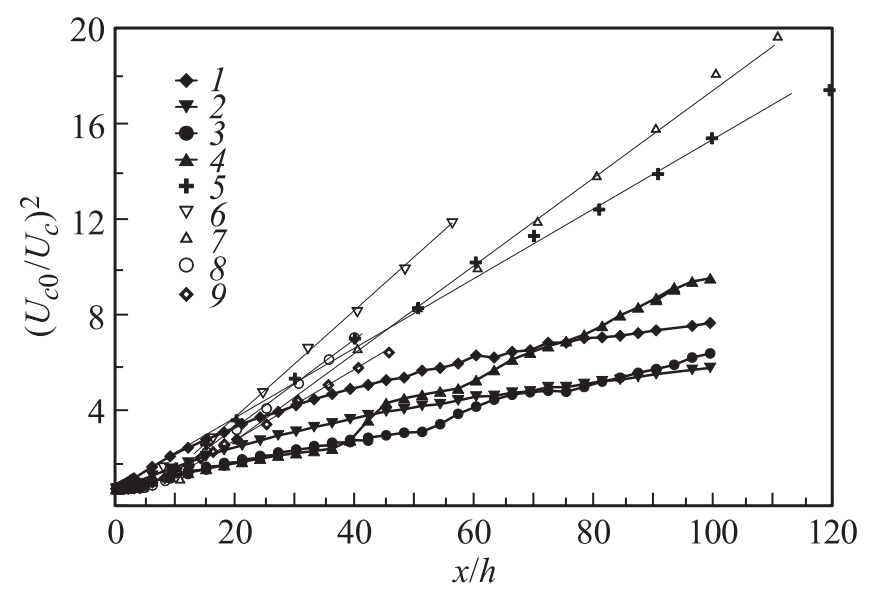

Pис. 2. Темп падения скорости на осевой линии струи (обозначения кривых в подписи к рис. 1).

Narishige NT-88E в диапазоне расстояний $x / h$ от 0 до 100. Положение датчика контролировалось с помощью стереоскопического микроскопа Nikon SMZ1500. Использовался воздух комнатной температуры в качестве рабочего газа. Поток газа задавался регулятором расхода Bronkhorst EL-Flow. Средняя скорость газа на срезе сопла составляла от 11 до 28.7 m/c. Максимальное число Рейнольдса, достигнутое в экспериментах, определялось максимальным значением регулятора расхода и составляло 154. Дозвуковая струя истекала в атмосферу, боковые стенки у струи отсутствовали.

На рис. 1 приведено распределение скорости газа вдоль осевой линии струи в линейном и логарифмическом масштабах. Здесь $U_{c}-$ скорость газа на осевой линии, $U_{c o}-$ скорость газа на срезе сопла. При $\mathrm{Re}=58$ и 88 (рис. $1, a$ ) наблюдается плавное изменение скорости во всем исследованном диапазоне $x / h$, в то время как при $\operatorname{Re}=130$ и 154 видны участки различного темпа изменения скорости. На рис. $1, b$ показаны те же данные, но в логарифмическом масштабе и в сравнении с данными турбулентных струй макроразмера [9-14]. Необходимо отметить, что если для турбулентных макроструй область потенциального течения составляет 5-6 калибров сопла, то для микроструй, в зависимости от числа Рейнольдса, эта область изменяется от 3 до 0.4

Письма в ЖТФ, 2017, том 43, вып. 14 


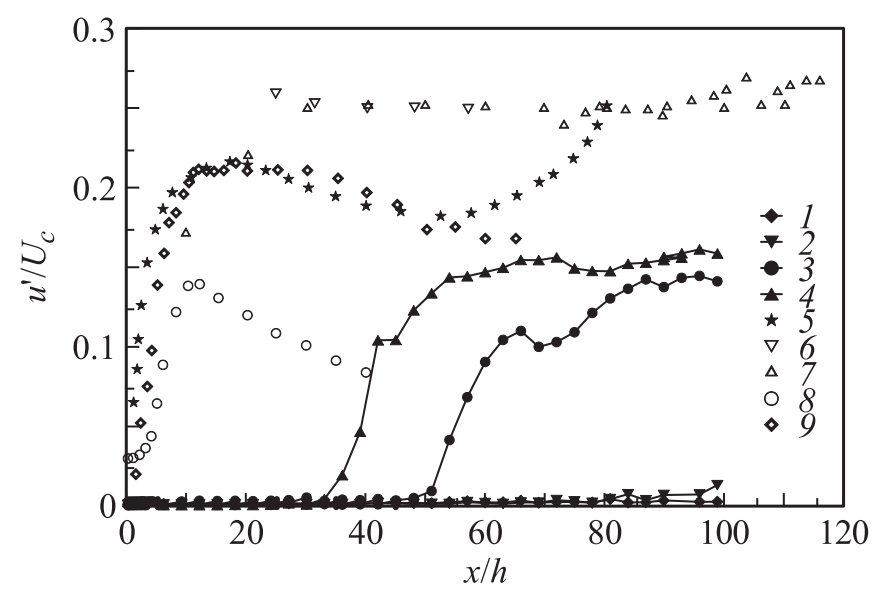

Рис. 3. Уровень турбулентности на осевой линии струи. $5-[14], h / w=40$, $\operatorname{Re}=3700$ (обозначения остальных кривых в подписи к рис. 1).

калибров. Это приводит к тому, что на начальном участке микроструи $(0<x / h<10-20)$ скорость падает несколько быстрее, чем в случае турбулентной струи.

Несмотря на различные числа Рейнольдса, для турбулентных струй имеется область падения скорости, характеризующаяся наклоном $(x / h)^{-0.5}$ (рис. $\left.1, b\right)$. Темп падения скорости турбулентных струй принято характеризовать тангенсом угла наклона зависимости $\left(U_{c o} / U_{c}\right)^{2}$ от $x / h$. Такая зависимость приведена на рис. 2. Видно, что для турбулентных струй существует разброс по углу наклона зависимости $\left(U_{c o} / U_{c}\right)^{2}$ от $x / h$, объясняемый главным образом различными типами сопел и различным начальным уровнем турбулентности. Однако для ламинарных микроструй темп падения скорости совершенно иной. Он характеризуется существенной нелинейностью и ярко выраженной зависимостью от числа Рейнольдса: чем меньше число Рейнольдса, тем интенсивнее падение скорости на осевой линии. В целом темп падения скорости ламинарных микроструй значительно меньше, чем турбулентных (исключая начальную область струи $0<x / h<10-20$, где проявляется малая величина области потенциального течения).

На рис. 3 представлен уровень турбулентности вдоль осевой линии струй. Видно, что на выходе из сопла уровень турбулентности в

Письма в ЖТФ, 2017, том 43, вып. 14 
микроструях практически на порядок меньше, чем для турбулентных макроструй. Низкий уровень турбулентности характерен для ламинарных течений. Когда число Рейнольдса составляет 154 , при $x / h \cong 36$ происходит резкий рост уровня турбулентности, приводящий впоследствии к турбулизации микроструи. Именно при значении $x / h \cong 36$ происходит заметное изменение темпа падения скорости струи (рис. 1,a). При $x / h>63$ уровень турбулентности практически не меняется. Таким образом, при $\mathrm{Re}=154$ можно выделить три области: область ламинарного течения микроструи $(x / h<36)$, область ламинарно-турбулентного перехода $(36<x / h<63)$ и область турбулентного течения микроструи $(x / h>63)$. Все три области прослеживаются на темпе падения скорости на осевой линии струи (рис. $1, a)$.

При $\mathrm{Re}=130$ также наблюдается ламинарно-турбулентный переход, начало которого характеризуется резким ростом уровня турбулентности, и происходит он дальше от среза сопла, при $x / h \cong 53$. Из графика ясно, что область турбулентного течения струи начинается за пределами диапазона измерений.

Положение ламинарно-турбулентного перехода в зависимости от числа Рейнольдса, определенное термоанемометрическими измерениями в данной работе, согласуется с данными работы [7], в которой положение ламинарно-турбулентного перехода в мини- и микроструях определялось методами визуализации течения: PIV- и LIF-методами.

При $\mathrm{Re}=88$ в конце исследованного диапазона расстояний наблюдается незначительный рост уровня турбулентности, связанный, повидимому, также с началом ламинарно-турбулентного перехода. При $\operatorname{Re}=58$ струя остается ламинарной во всем диапазоне достигнутых расстояний $x / h$.

Таким образом, в работе показано существенное отличие поведения плоских микроструй от турбулентных макроструй. Выявлено, что в целом темп падения скорости микроструй меньше, чем макроструй, что позволяет микроструям переносить свой импульс на большее относительное расстояние. Значительное изменение уровня турбулентности вдоль осевой линии позволяет определить области ламинарного, переходного и турбулентного течений. Для расширения представления о структуре и поведении ламинарных струй микронных размеров требуется проведение дополнительных комплексных исследований.

Работа выполнена при частичной поддержке гранта РНФ № 17-1901157.

Письма в ЖТФ, 2017, том 43, вып. 14 


\section{Список литературы}

[1] Aniskin V.M., Mironov S.G., Maslov A. A., Tsyryulnikov I. S. // Microfluid. Nanofluid. 2015. V. 19. I. 3. P. 621-634.

[2] Анискин В.М., Маслов А.А., Миронов С.Г. и др. // Письма в ЖТФ. 2015. T. 41. B. 10. C. $97-103$.

[3] Aniskin V.M., Mironov S.G., Maslov A.A. // Microfluid. Nanofluid. 2013. V. 14. I. 3. P. 605-614.

[4] Gau C., Shen C.H., Wang Z.B. // Phys. Fluids. 2009. V. 21. Art. № 092001.

[5] Chang C.J., Shen C.H., Gau C. // Nanoscale Microscale Thermophys. Eng. 2013. V. 17. P. $50-68$.

[6] Грек Г.Р., Козлов В.В., Литвиненко Ю.А. Устойчивость дозвуковых струйных течений и горение. Новосибирск, 2013. 240 с.

[7] Анискин В.М., Леманов В.В., Маслов Н.А и др. // Письма в ЖТФ. 2015. T. 41. B. 1. C. $94-101$.

[8] Deo C.R. Experimental Investigations of the Influence of Reynolds Number and Boundary Conditions on a Plane Air Jet. PhD Thesis, 2005.

[9] Sforza P.M., Steiger M.H., Trentacoste N. // AIAA J. 1966. V. 4. N 5. P. 800806.

[10] Bashir J., Uberoi M.S. // Phys. Fluids. 1975. V. 18. N 4. P. 405-410.

[11] Gutmark E., Wygnanski I. // J. Fluid Mech. 1976. V. 73. N 3. P. 465-495.

[12] Hussain A.K.M.F., Clark A.R. // Phys. Fluids. 1977. V. 20. N 9. P. 1416-1426.

[13] Deo R.C., Mi J., Nathan G.J. // Exp. Thermal Fluid Sci. 2007. V. 31. P. 825-838.

[14] Sfeir A. // AIAA J. 1979. V. 17. N 10. P. 1055-1060.

Письма в ЖТФ, 2017, том 43, вып. 14 